\title{
Association between Abdominal Wall Fat Index on Ultrasonography and Carotid Atherosclerosis in Non-obese Men
}

\author{
Ryuichi Kawamoto, Yuichiro Oka, Hitomi Tomita, Akihiro Kodama, and Naoko Ootsuka
}

Department of Internal Medicine, Nomura Municipal Hospital, Ehime, Japan.

\begin{abstract}
We tried to investigate whether accumulation of visceral fat, assessed by a simple but widely used ultrasonographic method, was associated with common carotid atherosclerosis in non-obese men ranging from 16 to 79 years old. The subjects were consecutive 297 male in-patients whose body mass index ranged from $18.5 \mathrm{~kg} / \mathrm{m}^{2}$ to 25 $\mathrm{kg} / \mathrm{m}^{2}$. An ultrasonographic evaluation using a 7.5 MHz linear type B-mode probe was performed by a specialist to determine the intima-media thickness (IMT) of the common carotid artery and the maximal thickness of peritoneal fat (Pmax) at the anterior surface of the liver and the minimal thickness of subcutaneous fat (Smin) of the abdomen. The Pmax/Smin ratio, which was termed the abdominal wall fat index (AFI), was then calculated. The mean age \pm standard deviation in this series was $65 \pm 13$ (range, $15-79)$ years. Multiple regression analysis using IMT as an objective variable, adjusted by various risk factors as explanatory variables, showed that AFI [ $\beta, 0.0538 ; 95 \%$ confidence interval (CI), 0.0116-0.0960 ] was a significant independent contributing factor along with known risk factors such as age, smoking status, systolic blood pressure, HDL-cholesterol and LDL-cholesterol. We found that AFI was useful in evaluating disorders of metabolism and atherosclerosis in non-obese men. J Atheroscler Thromb, 2005; 12: 85-91.
\end{abstract}

Key words: Intima-media thickness, Risk factor, Common carotid artery, Visceral fat

\section{Introduction}

The distribution of body fat has been reported to be closely related to metabolic disorders. However, the degree of obesity is not necessarily correlated with the severity and frequency of such disorders. Ito et al. (1) reported that excess accumulation of fat mass, especially in the upper body, was related to dyslipidemia in normal-weight Japanese individuals. Moreover, intra-abdominal adiposity has been found to be associated with glucose intolerance, elevated triglyceride (TG), low HDL cholesterol (HDL-C) levels, and hypertension in both clini-

This work was supported in part by a grant-in-aid (2004) from the Foundation for Development of Community.

Address for correspondence: Ryuichi Kawamoto, Department of Internal Medicine, Seiyo Municipal Nomura Hospital, 9-53 Nomura, Nomura-cho, Seiyo-city, Ehime 797-1212, Japan.

E-mail: rykawamo@yahoo.co.jp

Received August 12, 2004.

Accepted for publication September 21, 2004. cal (2) and population-based prospective cohort studies (3). Recently, Fujimoto et al. (4) reported that intraabdominal visceral fat, as well as blood pressure and plasma glucose, are important independent risk factors for incident coronary heart disease in this population of diabetic and nondiabetic Japanese-American men. Measurement of such accumulation is therefore an important step in assessing risks of atherosclerosis. However, the alternative of computed tomography (CT) scanning (2-4) and magnetic resonance imaging (5) can offer a better estimation, but exposure to high radiation levels, cost and technical difficulty are major disadvantages. Alternative noninvasive methods to quantify regional adiposity have been used in clinical and epidemiological studies. The use of waist-to-hip ratio (WHR) or waist circumference (1), and abdominal fat deposition by ultrasonography $(6,7-9)$ as predictors of atherosclerotic risk have been reported.

Recently, we demonstrated that measuring the preperitoneal and subcutaneous fat thickness by ultrasonogra- 
phy could reflect body fat distribution more accurately, and was useful in evaluating disorders of metabolism, hypertension and atherosclerosis in non-obese as well as obese women (9). In obese men, several studies have showed that intra-abdominal visceral fat accumulation determined by CT scanning may be related to the appearance of these risk factors and contribute to the development of atherosclerosis (10-11). However, to our knowledge, few studies have focused on the measurement of preperitoneal and subcutaneous fat thickness by ultrasonography in non-obese men. Therefore, this study assessed the accumulation of visceral fat by ultrasonography and determined its relation to various risk factors for atherosclerosis as well as its association with common carotid atherosclerosis in non-obese men.

\section{Materials and Methods}

\section{Subjects}

The subjects were consecutive male in-patients in the Medical Department of Seiyo Municipal Nomura Hospital enrolled between September 1996 and August 2004. Men, aged from 15 to 79 years, with body mass index (BMI) from 18.5 to $25 \mathrm{~kg} / \mathrm{m}^{2}$ were screened for inclusion in the study. Patients with a history of upper abdominal surgery were excluded to avoid any possible effect on measurement of fat thickness. Informed consent for the procedure was obtained from each patient. The subjects were 297 men aged $65 \pm 13$ (range, 15-79) years.

\section{Ultrasound image analysis}

An ultrasonographic evaluation (Hitachi EUB-565) using a $7.5 \mathrm{MHz}$ linear type B-mode probe was performed by a specialist to evaluate sclerotic lesions of the common carotid arteries and fat thickness on a day close to the day of blood biochemistry analysis (within 2 days). Patients were placed in supine position, and the bilateral carotid arteries were observed obliquely from the anterior and posterior directions. We measured the thickness of the intima-media complex (IMT) on the far wall of the bilateral common carotid artery about $10 \mathrm{~mm}$ proximal to the bifurcation of the carotid artery (as the image at that site is more clearly depicted compared with that of the near wall) $(12,13)$ as well as the wall thickness near the $10 \mathrm{~mm}$ point on the B-mode monitor, then used the mean value for analysis. To investigate the relation between IMT and various factors, all subjects were divided into three groups based on tertile of IMT.

Regarding the measurement of fat thickness, the subjects were placed in a supine position, the probe was held perpendicular to the skin at the epigastrium, and vertical scanning was performed along the abdominal median from the processus xiphoideus to the umbilicus to measure the maximal thickness of preperitoneal fat (Pmax) at the anterior surface of the liver and the mini- mal thickness of the subcutaneous fat (Smin) of the abdomen. Then the Pmax/Smin ratio (abdominal wall fat index, AFI) was calculated (14).

\section{Other various risk factors}

We measured systolic (SBP) and diastolic blood pressure (DBP) in the right upper arm of patients in a seated posture using an automatic oscillometric blood pressure recorder (UA-766, AND Co. Ltd, Tokyo, Japan). Cigarette smoking was quantified based on daily consumption and duration of smoking. For blood biochemistry analyses, total cholesterol (T-C), TG and HDL-C, uric acid were measured under a fasting condition within 24 hours of admission. LDL cholesterol (LDL-C) level was calculated by the Friedewald formula. History of use of antihypertensive and antilipidemic drugs was also evaluated. The presence of diabetes mellitus was defined as a history of treatment for diabetes mellitus.

Criteria for the determination of atherosclerotic risk factors were as follows:

- Hypertension shown by administration of antihypertensive drugs.

- Diabetes mellitus revealed by the use of hypoglycemic drugs or insulin therapy, or case history.

- Hypertriglyceridemia shown by TG concentrations higher than $150 \mathrm{mg} / \mathrm{dl}$.

- High LDL-C level shown by LDL-C concentrations higher than $140 \mathrm{mg} / \mathrm{dl}$ or the use of antilipidemic drugs. - Low HDL-C level shown by HDL-C less than $40 \mathrm{mg} / \mathrm{dl}$. To investigate the relationships between AFI and the involvement of multiple atherosclerotic risk factors (metabolic syndrome + high LDL-C), we calculated the sum of the above risk factor scores giving one point for each of the five items if present (risk factor morbidity index).

\section{Statistical analysis}

Statistical analysis was performed using SPSS 10.0J (Statistical Package for Social Science, Inc., Chicago, IL, USA). Differences among three groups divided based on IMT (IMT-1, 0.48-0.85 mm; IMT-2, 0.86-1.04 mm; IMT$3,1.05-2.23 \mathrm{~mm}$ ) were analyzed by one-way ANOVA or $\chi^{2}$-test. Correlations between various characteristics and IMT were made using Pearson's correlation test. The relation between IMT and risk factors including AFI were examined by stepwise multiple linear regression analysis. A value of $p<0.05$ was considered significant.

\section{Results}

Table 1 shows the background characteristics of the three groups divided by IMT. Age $(p<0.001)$, smoking status $(p=0.008), \operatorname{SBP}(p<0.001)$, antihypertensive drug use $(p<0.001), \mathrm{T}-\mathrm{C}(p=0.001), \mathrm{HDL}-\mathrm{C}(p=0.014)$, LDLC $(p<0.001)$, risk factor morbidity index $(p<0.001)$ and atherosclerotic disease $(p<0.001)$ were higher in the 
Table 1. Characteristics of subjects by carotid intima-media thickness.

\begin{tabular}{|c|c|c|c|c|}
\hline & $\begin{array}{c}\text { IMT-1 } \\
(0.48-0.85)\end{array}$ & $\begin{array}{c}\text { IMT-2 } \\
(0.86-1.04)\end{array}$ & $\begin{array}{c}\text { IMT-3 } \\
(1.05-2.23)\end{array}$ & \\
\hline Characteristics & $n=105$ & $n=97$ & $n=95$ & $p$-value ${ }^{\S}$ \\
\hline Age (years) & $57 \pm 16$ & $68 \pm 8$ & $69 \pm 7$ & $<0.001$ \\
\hline Body mass index $\left(\mathrm{kg} / \mathrm{m}^{2}\right)$ & $22 \pm 2$ & $22 \pm 2$ & $22 \pm 2$ & 0.094 \\
\hline Smoking status & $23 \pm 22$ & $30 \pm 24$ & $33 \pm 27$ & 0.008 \\
\hline Systolic blood pressure (mmHg) & $126 \pm 19$ & $136 \pm 21$ & $143 \pm 23$ & $<0.001$ \\
\hline Diastolic blood pressure (mmHg) & $76 \pm 12$ & $78 \pm 12$ & $79 \pm 12$ & 0.132 \\
\hline Antihypertensive drug use, $N(\%)$ & $22(21.0)$ & $47(48.5)$ & $49(51.6)$ & $<0.001$ \\
\hline Total cholesterol (mg/dl) & $166 \pm 44$ & $164 \pm 41$ & $185 \pm 44$ & 0.001 \\
\hline Triglyceride (mg/dl) & $104 \pm 74$ & $88 \pm 45$ & $106 \pm 51$ & 0.068 \\
\hline HDL-cholesterol (mg/dl) & $52 \pm 19$ & $48 \pm 20$ & $44 \pm 18$ & 0.014 \\
\hline LDL-cholesterol (mg/dl) & $93 \pm 38$ & $98 \pm 35$ & $120 \pm 39$ & $<0.001$ \\
\hline Antilipidemic drug use, $N(\%)$ & 0 & $1(1.0)$ & $5(4.2)$ & 0.057 \\
\hline Uric acid (mg/dl) & $5.4 \pm 1.6$ & $5.6 \pm 1.7$ & $5.8 \pm 1.8$ & 0.222 \\
\hline Diabetes mellitus, $N(\%)$ & $25(23.8)$ & $23(23.7)$ & $28(29.5)$ & 0.575 \\
\hline Risk factor morbidity index & $1.0 \pm 1.0$ & $1.2 \pm 0.9$ & $1.8 \pm 1.0$ & $<0.001$ \\
\hline Smin $(\mathrm{mm})$ & $8.5 \pm 3.1$ & $8.5 \pm 3.3$ & $8.3 \pm 2.5$ & 0.823 \\
\hline $\operatorname{Pmax}(\mathrm{mm})$ & $7.6 \pm 3.1$ & $8.1 \pm 3.4$ & $8.4 \pm 3.8$ & 0.279 \\
\hline Abdominal wall fat index & $0.95 \pm 0.40$ & $1.05 \pm 0.57$ & $1.09 \pm 0.60$ & 0.138 \\
\hline Atherosclerotic disease, $N(\%)$ & $14(13.3)$ & $37(38.1)$ & $47(49.5)$ & $<0.001$ \\
\hline Ischemic stroke, $N(\%)$ & $11(10.5)$ & $28(28.9)$ & $39(41.1)$ & $<0.001$ \\
\hline Ischemic heart disease, $N(\%)$ & $4(3.8)$ & $10(10.3)$ & $11(11.6)$ & 0.102 \\
\hline
\end{tabular}

Plus-minus values are means $\pm \mathrm{SD}$. ${ }^{\dagger}$ : Body mass index is the weight in kilograms divided by the square of the height in meters. : Smoking status: daily consumption (packs) $\times$ duration of smoking (years). IMT: carotid intima-media thickness. Pmax: the maximal thickness of peritoneal fat at the anterior surface of the liver; Smin: the minimal thickness of subcutaneous fat of the abdomen. \$: one-way ANOVA or $\chi^{2}$-test.

groups with higher IMT. There were no inter-group differences in BMI, DBP, TG, Antilipidemic drug use, uric acid, presence of diabetes mellitus, Smin, Pmax and AFI.

Table 2 shows a correlation coefficient between their background characteristics and IMT. Age $(p<0.001)$, smoking status $(p<0.001)$, SBP $(p<0.001)$, antihypertensive drug use $(p<0.001), \mathrm{T}-\mathrm{C}(p=0.009), \mathrm{HDL}-\mathrm{C}(p=$ $0.010)$, LDL-C $(p<0.001)$ and antilipidemic drug use $(p=$ $0.038)$, uric acid $(p=0.020)$ and $\operatorname{AFI}(p=0.016)$ were significantly correlated with IMT.

Figure 1 shows a correlation between the AFI, Pmax, Smin, age, SBP and LDL-C and IMT. The correlation coefficient between the AFI, age, SBP and LDL-C, and IMT were significant. On the other hand, the correlation between the Pmax and Smin, and IMT were not significant.

Figure 2 shows the subjects' risk factor morbidity in- dex in relation to the AFI. The risk factor morbidity index of the group with the highest AFI was significantly more than that of the group with the lowest AFI $(p=0.007)$.

Multiple regression analysis using IMT as an objective variable, adjusted by various risk factors as explanatory variables, showed that AFI $[\beta, 0.0538 ; 95 \%$ confidence interval (CI), 0.0116-0.0960] was a significant independent contributing factor along with known risk factors such as age, smoking status, SBP, HDL-C and LDLC (Table 3).

\section{Discussion}

The results of our investigation show that in a sample of men selected with regard to normal BMI, AFI which was the Pmax/Smin ratio, was a significant independent contributing factor to metabolic disorders, along with 
Table 2. Correlation between various characteristics and carotid intima-media thickness.

\begin{tabular}{|c|c|c|}
\hline Characteristics & $\begin{array}{l}\text {-media thickness } \\
\text { lation coefficient }\end{array}$ & $p$-value $\S$ \\
\hline Age (years) & 0.470 & $<0.001$ \\
\hline Body mass index $\left(\mathrm{kg} / \mathrm{m}^{2}\right)$ & 0.052 & 0.374 \\
\hline Smoking status & 0.258 & $<0.001$ \\
\hline Systolic blood pressure (mmHg) & 0.313 & $<0.001$ \\
\hline Diastolic blood pressure $(\mathrm{mmHg})$ & 0.097 & 0.097 \\
\hline $\begin{array}{l}\text { Antihypertensive drug use } \\
\quad(\text { Yes }=1, \text { No }=0)\end{array}$ & 0.276 & $<0.001$ \\
\hline Total cholesterol (mg/dl) & 0.151 & 0.009 \\
\hline Triglyceride (mg/dl) & 0.035 & 0.552 \\
\hline HDL-cholesterol (mg/dl) & -0.149 & 0.010 \\
\hline LDL-cholesterol (mg/dl) & 0.233 & $<0.001$ \\
\hline $\begin{array}{l}\text { Antilipidemic drug use } \\
\quad(\text { Yes }=1, \text { No }=0)\end{array}$ & 0.120 & 0.038 \\
\hline Uric acid (mg/dl) & 0.135 & 0.020 \\
\hline $\begin{array}{l}\text { Diabetes mellitus } \\
\qquad(\text { Yes }=1, \text { No }=0)\end{array}$ & 0.026 & 0.655 \\
\hline Abdominal wall fat index & 0.140 & 0.016 \\
\hline Pmax & 0.097 & 0.094 \\
\hline Smin & -0.044 & 0.454 \\
\hline
\end{tabular}

": Body mass index is the weight in kilograms divided by the square of the height in meters. Smoking status: daily consumption (packs) $\times$ duration of smoking (years). An addictive model (Yes $=1$, No = 1) were used for antihypertensive and antilipidemic drug use. Pmax: the maximal thickness of peritoneal fat at the anterior surface of the liver; Smin: the minimal thickness of subcutaneous fat of the abdomen. ${ }^{\S}$ : Pearson's correlation test.

known risk factors such as age, smoking status, systolic blood pressure, HDL-C and LDL-cholesterol. The investigation also showed that the maximal thickness of preperitoneal fat (Pmax) and the minimum thickness of subcutaneous fat (Smin) in the abdomen could be determined by ultrasonography, useful in evaluating carotid atherosclerosis.

Yamamoto et al. (15) reported that visceral fat accumulation (Pmax) assessed by ultrasonography may play a role in the progression of IMT in non-obese middle-aged men, but AFI was not correlated with IMT. However, in our study, IMT was associated with AFI rather than Pmax. We have already reported that ultrasonographically determined AFI in women is related to SBP, DBP, T-C and TG, and is an independent risk factor for IMT (9). In this study, AFI also showed good correlation with risk factor scores (metabolic syndrome + high LDL-C) in non-obese men with a BMl from 18.5 to $25 \mathrm{~kg} / \mathrm{m}^{2}$ as well as women with a BMI over $22.0 \mathrm{~kg} / \mathrm{m}^{2}$ (9). Furthermore, $\mathrm{AFI}$ is a risk factor for coronary heart disease because the severity of coronary stenosis for both men and women was higher in the high-AFI groups than in the low-AFI groups (16). Abdominal wall fat index, which we chose as a tool for expressing the fat distribution in the abdomen, was strongly related to the atherosclerotic risk factor and carotid atherosclerosis in non-obese men.

Alternative non-invasive methods to quantify regional adiposity have been developed in screening and epidemiological studies, in consideration of exposure to radiation, and the great expense and low availability of CT. Therefore, the use of BMI (17), waist-to-hip circumference ratio (1), waist circumference (1-18), body composition dual-energy $\mathrm{x}$-ray absorptiometry (19), waist/height ratio (20) and more recently abdominal fat deposition by ultrasonography are utilized as simple and common methods of measuring abdominal obesity $(2,6-9,14,15)$. Okada et al. (17) demonstrated that IMT was independently correlated with BMI, T-C, HDL-C, LDL-C and SBP in males and with BMI, T-C, TG, HDL-C, LDL-C, HbA1c, SBP, and DBP in females. Han et al. (18) reported that larger waist circumference increased cardiovascular risks in 2183 men and 2698 women aged $20-59$ years selected at random from the civil registry of Amsterdam and Maastricht. However, Hsieh et al. (20) suggested that the weight/height ratio may be a better predictor of multiple coronary heart disease risk factors such as blood pressure, fasting plasma glucose, hemoglobin $A_{1 c}, T G, T-C$ and HDL-C than BMI or the waist/hip ratio. We used a simple, widely available ultrasound device to assess the maximal thickness of preperitoneal fat (Pmax) and the minimal thickness of subcutaneous fat (Smin). Pmax was significantly correlated with visceral fat measurement by CT at the umbilical level $(r=0.70, p<0.001)$ and Smin, the subcutaneous fat area $(r=0.83, p<0.001)(14)$. In the present study, AFI is positively correlated with the risk factor morbidity index. AFI is strongly associated with IMT adjusted for other atherosclerotic risk factors. These data suggest that AFI based on visceral fat accumulation in non-obese men may be an important predictor of IMT.

Body fat accumulation has been shown to be an important predictor of atherosclerosis, and the complexity of this relationship has been illustrated in recent studies in which regional adiposity on body was more closely associated with atherosclerosis incidence than was the magnitude of generalized obesity $(1-11,15,16)$. Visceral obesity or visceral fat accumulation without obesity is closely associated with what Matsuzawa et al. (21) describes as "visceral fat syndrome", or what Reaven (22) describes as "Syndrome X", such metabolic and circulatory disorders as insulin resistance, glucose intolerance, 

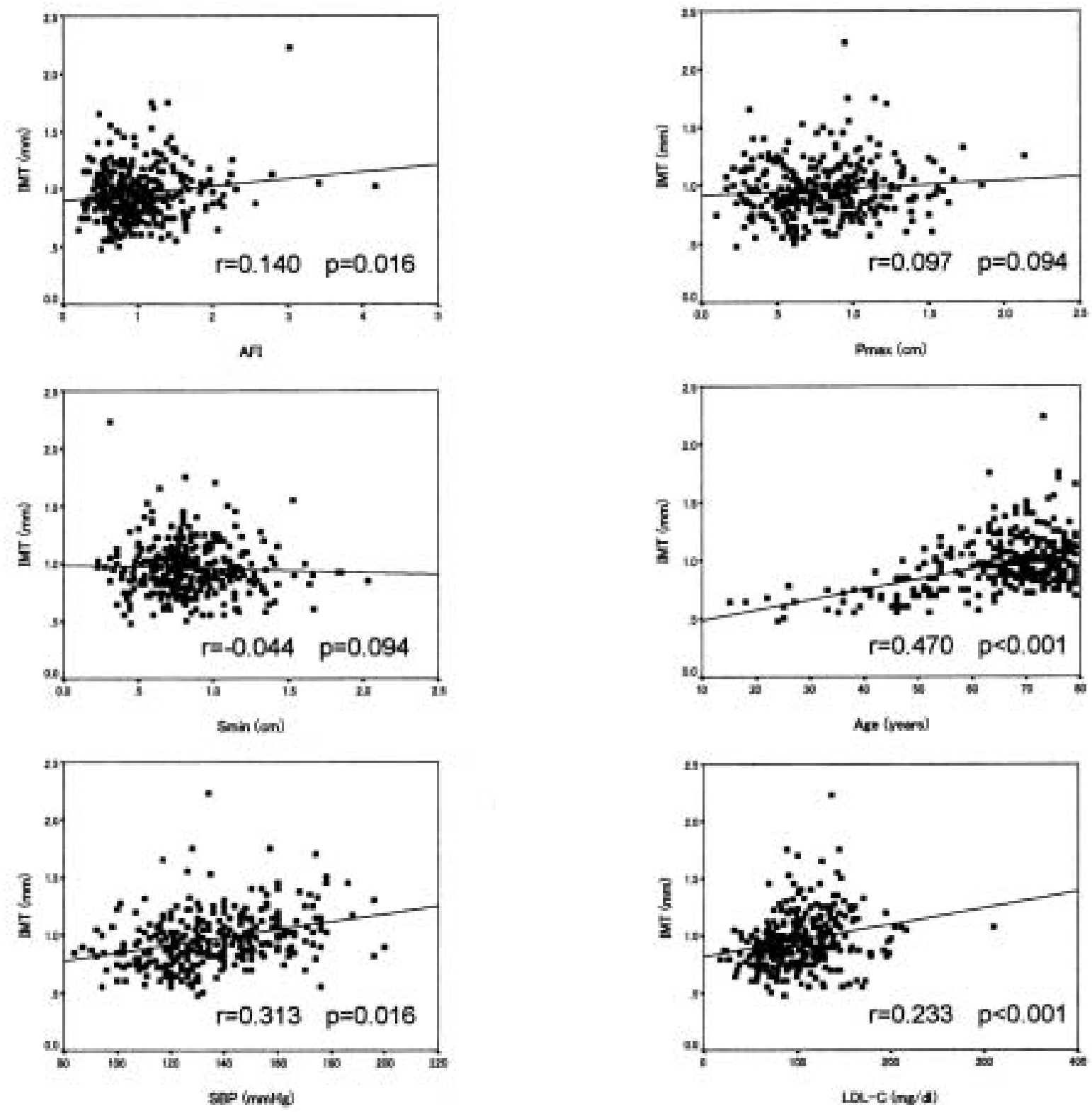

Fig. 1. Correlation between abdominal wall fat index (AFI), the maximal thickness of preperitoneal fat (Pmax) at the anterior surface of the liver, the minimal thickness of the subcutaneous fat of the abdomen (Smin), age, systolic blood pressure (SBP) and LDL-cholesterol (LDL-C), and carotid intima-media thickness (IMT).

hypertriglyceridemia, hypertension, decreased plasma concentration of HDL-C and increased plasma concentration of LDL-C. We also observed this finding in relation to visceral fat accumulation group by ultrasonography, which reinforces the role of AFI in the identification of people at high risk for carotid atherosclerosis.

Thus, the question is why increased visceral fat results in the progression of atherosclerosis. The function of adipocytes has been proven to differ according to location. Adipocytes of fat accumulated in the peritoneum and other visceral locations are metabolically active and exhibit a higher rate of lipolysis by catecholamines or facilitation of lipid mobilization compared to cells obtained from subcutaneous adipose tissue $(23,24)$. It has been shown that visceral fat accumulation that is mainly composed of omental and mesenteric adipocytes is closely related to metabolism in the liver. Release of excessive free fatty acids into portal circulation causes overproduction of very low density lipoprotein (VLDL) that may result in hypertriglyceridemia and hypercholesterolemia 

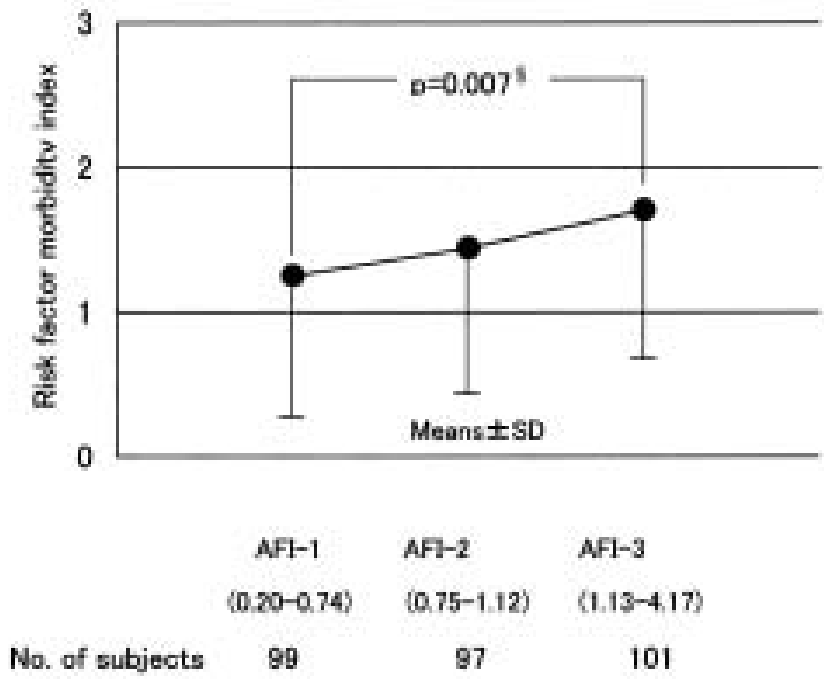

Fig. 2. Subject distribution and risk factor morbidity index in relation to the abdominal wall fat index (compared with the highest risk group by one-way ANOVA: $p=0.026)$. $\$$ : unpaired $t$ test. AFI: abdominal wall fat index.

(25). A reduction in insulin sensitivity of hepatocytes as well as disturbance of glucose metabolism may also be promoted. Recent advances in the biology of adipose tissue have demonstrated that adipose tissue is not an energy storage organ but secretes a variety of molecules which affect metabolism of the whole body $(26,27)$. This article found an effect of AFI on IMT after adjusting for other atherosclerotic risks. These metabolic disorders may result in promoting atherosclerosis over the long term.

In conclusion, we suggest that ultrasonographically determined AFI is a useful parameter for evaluating disorders in lipid metabolism and atherosclerosis in nonobese men.

Acknowledgement: This work was supported in part by a grant-in-aid from the Foundation for Development of Community (2002).

\section{References}

(1) Ito H, Nakasuga K, Ohshima A, Sakai Y, Maruyama T, Kaji Y, Harada M, Jingu S, and Sakamoto M: Excess accumulation of body fat is related to dyslipidemia in normal-weight subjects. Int $\mathrm{J}$ Obes Relat Metab Disord, 28: 242-247, 2004

( 2 ) Boyko EJ, Leonetti DL, Bergstrom RW, Newell-Morris L, and Fujimoto WY: Visceral adiposity, fasting plasma insulin, and lipid and lipoprotein levels in Japanese Americans. Int J Obes Relat Metab
Table 3. Relation between conventional risk factors and carotid atherosclerosis as determined by multiple linear regression analysis.

\begin{tabular}{lcr}
\hline Characteristics & beta $(95 \% \mathrm{Cl})$ & -value \\
\hline Age (years) & $0.0070(0.0052-0.0088)$ & $<0.001$ \\
Smoking status & $0.0015(0.0006-0.0025)$ & 0.001 \\
$\begin{array}{l}\text { Systolic blood } \\
\text { pressure (mmHg) }\end{array}$ & $0.0022(0.0011-0.0032)$ & $<0.001$ \\
$\begin{array}{l}\text { HDL-cholesterol } \\
\text { (mg/dl) }\end{array}$ & $-0.0013(-0.0025--0.0002)$ & 0.025 \\
$\begin{array}{c}\text { LDL-Cholesterol } \\
\text { (mg/dl) }\end{array}$ & $0.0011(0.0005-0.0016)$ & $<0.001$ \\
$\begin{array}{c}\text { Abdominal wall fat } \\
\text { index }\end{array}$ & $0.0538(0.0116-0.0960)$ & 0.013 \\
\hline
\end{tabular}

$\mathrm{Cl}$ : confidence interval. Body mass index, diastolic blood pressure, antihypertensive drug use, total-cholesterol, triglyceride, antilipidemic drug use, uric acid and presence of diabetes mellitus were not included in final model by stepwise multiple linear regression analysis.

Disord, 20: 801-808, 1996

( 3 ) Hayashi T, Boyko EJ, Leonetti DL, McNeely MJ, Newell-Morris L, Kahn SE, and Fujimoto WY: Visceral adiposity is an independent predictor of incident hypertension in Japanese Americans. Ann Intern Med, 140: 992-1000, 2004

( 4 ) Fujimoto WY, Bergstrom RW, Boyko EJ, Chen KW, Leonetti DL, Newell-Morris L, Shofer JB, and Wahl PW: Visceral adiposity and incident coronary heart disease in Japanese-American men. The 10-year follow-up results of the Seattle Japanese-American Community Diabetes Study. Diabetes Care, 22: 1808-1812, 1999

( 5 ) Ohsuzu F, Takayama E, Hayashi K, Yanagida S, Nomi M, Kosuda S, Kusano S, and Nakamura H: Relation of abdominal and thigh adipose tissue distribution to serum lipids and glucose metabolism in obese males. J Atheroscler Thromb, 4: 34-39, 1997

(6) Liu KH, Chan YL, Chan WB, Kong WL, Kong MO, and Chan JC: Sonographic measurement of mesenteric fat thickness is a good correlate with cardiovascular risk factors: comparison with subcutaneous and preperitoneal fat thickness, magnetic resonance imaging and anthropometric indexes. Int J Obes Relat Metab Disord, 27: 1267-1273, 2003

( 7 ) Leite CC, Wajchenberg BL, Radominski R, Matsuda D, Cerri GG, and Halpern A: Intra-abdominal thickness by ultrasonography to predict risk factors for cardiovascular disease and its correlation with anthropometric measurements. Metabolism, 51: 
1034-1040, 2002

( 8 ) Kim SK, Kim HJ, Hur KY, Choi SH, Ahn CW, Lim SK, Kim KR, Lee HC, Huh KB, and Cha BS: Visceral fat thickness measured by ultrasonography can estimate not only visceral obesity but also risks of cardiovascular and metabolic diseases. Am J Clin Nutr, 79: 593-599, 2004

( 9 ) Kawamoto R, Kajiwara T, Oka Y, and Takagi Y: Association between abdominal wall fat index and carotid atherosclerosis in women. $J$ Atheroscler Thromb, 9: 213-218, 2002

(10) Fujioka S, Matsuzawa Y, Tokunaga K, and Tarui S: Contribution of intra-abdominal fat accumulation to the impairment of glucose and lipid metabolism in human obesity. Metabolism, 36: 54-59, 1987

(11) Yanagisawa K: The effects of body fat distribution on glucose tolerance in overweight subjects: glucose intolerance and insulin resistance induced by intra-abdominal fat accumulation. Nippon Naibunpi Gakkai Zasshi, 67: 1240-1251, 1991 (in Japanese, abstract in English)

(12) Sdhu PS and Desai SR: A simple and reproducible method for assessing intima-media thickness of the common carotid artery. British Journal of Radiology, 70: 85-89, 1997

(13) Salonen JT and Salonen R: Ultrasonographically assessed carotid morphology and the risk of coronary heart disease. Arter Throm, 11: 1245-1249, 1991

(14) Suzuki R, Watanabe S, Hirai Y, Akiyama K, Nishide $T$, Matsushima $Y$, Murayama $H$, Ohshima $H$, Shinomiya M, Shirai K, Saito Y, Yoshida S, Saisho $\mathrm{H}$, and Ohto $\mathrm{M}$ : Abdominal wall fat index, estimated by ultrasonography, for assessment of the ratio of visceral fat to subcutaneous fat in the abdomen. Amer J Med, 95: 309-314, 1993

(15) Yamamoto M, Egusa G, Hara H, and Yamakido M: Association of intraabdominal fat and carotid atherosclerosis in non-obese middle-aged men with normal glucose tolerance. Int J Obes Relat Metab Disord, 21: 948-951, 1997

(16) Suzuki R, Watanabe S, Nishide T, Matsushima Y, Ohshima H, Akiyama K, Murayama H, Inadera $\mathrm{H}$, Ishikawa Y, Shirai K, Saito Y, Yoshida S, Saisho H, and Ohto $\mathrm{M}$ : Correlation in intraabdominal fat accumulation and coronary stenosis: significance of abdominal wall fat index (AFI). Atherosclerosis, 20: 27-30, 1992 (in Japanese, abstract in English)

(17) Okada M, Miida T, Hama H, Yata S, Sunaga T,
Tsuda A, and Saito H: Possible risk factors of carotid artery atherosclerosis in the Japanese population: a primary prevention study in non-diabetic subjects. Intern Med, 39: 362-368, 2000

(18) Han TS, van Leer EM, Seidell JC, and Lean ME: Waist circumference action levels in the identification of cardiovascular risk factors: prevalence study in a random sample. BMJ, 311: 1401-1405, 1995

(19) Sopher AB, Thornton JC, Wang J, Pierson RN Jr, Heymsfield SB, and Horlick M: Measurement of percentage of body fat in 411 children and adolescents: a comparison of dual-energy X-ray absorptiometry with a four-compartment model. Pediatrics, 113: 1285-1290, 2004

(20) Hsieh SD, Yoshinaga $\mathrm{H}$ : Waist/height ratio as a simple and useful predictor of coronary heart disease risk factors in women. Internal Medicine, 34: 1147-1152, 1995

(21) Matsuzawa Y, Funahashi T, Kihara S, and Shimomura I: Adiponectin and metabolic syndrome. Arterioscler Thromb Vasc Biol, 24: 29-33. 2004

(22) Reaven GM: Multiple CHD risk factors in type 2 diabetes: beyond hyperglycaemia. Diabetes Obes Metab, 4: S13-S18, 2002

(23) Rebuffe-Scrive M, Anderson B, and Olbe L: Metabolism of adipose tissue in intraabdominal deposits in severely obese men and women. Metabolism, 39: 1021-1025, 1990

(24) Busetto L, Digito M, Dalla Monta P, Carraro R, and Enzi G: Omental and epigastric adipose tissue lipolytic activity in human obesity. Effect of abdominal fat distribution and relationship with hyperinsulinemia. Horm Metab Res, 25: 365-371, 1993

(25) Julius U: Influence of plasma free fatty acids on lipoprotein synthesis and diabetic dyslipidemia. Exp Clin Endocrinol Diabetes, 111: 246-250, 2003

(26) Ciccone M, Vettor R, Pannacciulli N, Minenna A, Bellacicco M, Rizzon P, Giorgino R, and De Pergola G: Plasma leptin is independently associated with the intima-media thickness of the common carotid artery. Int J Obes Relat Metab Disord, 25: 805-810, 2001

(27) Matsuda M, Kawasaki F, Yamada K, Kanda Y, Saito M, Eto M, Matsuki M, and Kaku K: Impact of adiposity and plasma adipocytokines on diabetic angiopathies in Japanese Type 2 diabetic subjects. Diabet Med, 21: 881-888, 2004 